\title{
CONFERENCIA
}

\section{INTEGRACIÓN LONGITUDINAL DE LA ENSEÑANZA DE LA ANATOMÍA A LO LARGO DE LA CARRERA DE MEDICINA.}

\author{
Stephen W. CARMICHAEL \\ Departamento de Anatomía, Centro Emérito, Mayo Clinic, Rochester, MN, Estados Unidos de Norte \\ América.
}

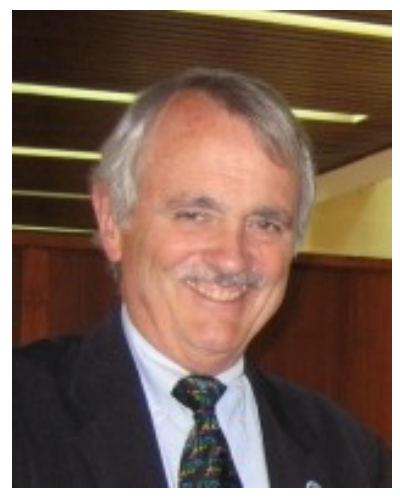

En las escuelas de medicina del mundo, la Anatomía se enseña a los estudiantes de primer año de Medicina (y otras profesiones) como un curso práctico. Esta actividad educativa ocupa habitualmente un período, que puede extenderse entre varias semanas y pocos meses. Esto deja algún tiempo y energía intelectual para incursionar en la investigación, pero es difícil competir con otras ciencias básicas que tienen menor carga horaria de enseñanza. Para expandir las actividades de anatomía, ofrecemos actividades opcionales para estudiantes avanzados o trabajo con estudiantes mayores que se desempeñan como Ayudantes Docentes. También podemos contar, para la docencia, con estudiantes de materias afines, residentes y médicos que regresan para su formación de post-grado. En la Escuela de Medicina de la Mayo Clinic, hemos incrementado efectivamente nuestras actividades con los residentes y los cursantes de post-grado, ya que la necesidad del conocimiento anatómico no se detiene cuando el nuevo médico se gradúa. Nosotros ofrecemos cursos de repaso para las subespecialidades quirúrgicas y algunas especialidades no quirúrgicas (como Anestesiología y Fisioterapia y Rehabilitación). Habitualmente, se organiza un curso para residentes, donde dos participantes efectúan una determinada disección, para una fecha especificada, y presentan esa región a los otros residentes, a un cirujano de planta y a un anatomista. La contribución de los anatomistas ha sido bienvenida por los colegas clínicos y apreciada por los residentes. Es nuestra responsabilidad obtener el conocimiento práctico adecuado para asistir a las disertaciones y seminarios, y sostener las discusiones con los clínicos. Ha sido necesario programar las sesiones fuera del horario habitual de trabajo (noches y fines de semana), pero nuestros esfuerzos han redundado en reconocimiento positivo al Departamento de Anatomía. De este modo, los anatomistas pueden contribuir a la misión educativa de sus instituciones y ganar respeto adicional por parte de sus colegas. 